\title{
Nd:YAG vitreolysis and pars plana vitrectomy: surgical treatment for vitreous floaters
}

YM Delaney, A Oyinloye, and L Benjamin

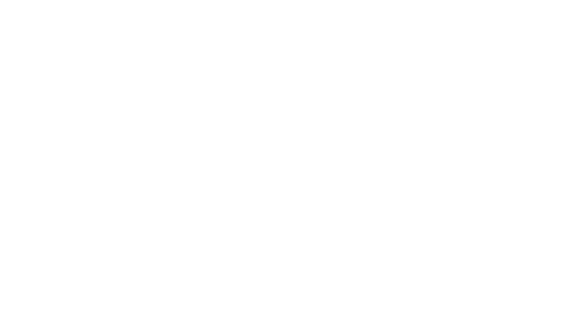

Abstract

Purpose of study To determine the efficacy of Nd:YAG vitreolysis and pars plana vitrectomy in the treatment of vitreous floaters.

Methods This is a single centre retrospective study of 31 patients (42 eyes) who underwent 54 procedures, Nd:YAG vitreolysis or pars plana vitrectomy, for the treatment of vitreous floaters between January 1992 and December 2000. Main outcome measures were percentage symptomatic improvement following treatment and incidence of post-operative complications. Statistical analysis was performed using the Fisher exact test. Results Posterior vitreous detachment was the primary cause of floaters in all 42 eyes with co-existing vitreous veils in three eyes and asteroid hyalosis in two eyes. Thirtynine of 42 eyes received Nd:YAG vitreolysis. Thirty-eight percent found Nd:YAG vitreolysis moderately improved their symptoms while $61.5 \%$ found no improvement. After an average of $\mathbf{1 4 . 7}$ months follow-up no post-operative complications were recorded. Fifteen eyes underwent a pars plana vitrectomy, one with combined phacoemulsification and posterior chamber implantation and $\mathbf{1 1}$ following unsuccessful laser vitreolysis. Pars plana vitrectomy resulted in full resolution of symptoms in $93.3 \%$ of eyes. One patient developed a post-operative retinal detachment which was successfully treated leaving the patient with $6 / 5 \mathrm{VA}$.

Conclusion Patients' symptoms from vitreous floaters are often underestimated resulting in no intervention. This paper shows Nd:YAG vitreolysis to be a safe but only moderately effective primary treatment conferring clinical benefit in one third of patients. Pars plana vitrectomy, while offering superior results, should be reserved for patients who remain markedly symptomatic following vitreolysis, until future studies further clarify its role in the treatment of patients with floaters and posterior vitreous detachment.

Eye (2002) 16, 21-26. DOI: 10.1038/

sj/EYE/6700026

Keywords: vitreous floaters; Nd:YAG vitreolysis; pars plana vitrectomy; posterior vitreous detachment

Vitreous floaters are most commonly caused by posterior vitreous detachment (PVD), $, 1,2$ vitreous syneresis ${ }^{2}$ and asteroid hyalosis. ${ }^{3}$ While these symptoms are considered physiological in nature they can be of considerable inconvenience to many patients. This is especially the case in myopes in whom PVD occurs at an earlier age ${ }^{4}$ and in whom symptoms may be more severe because of retinal image magnification. Nd:YAG vitreolysis $^{5,6}$ and pars plana vitrectomy $(\mathrm{PPV})^{7,8}$ have both been advocated as effective treatment for vitreous opacities. However it is our perception that many patients with symptomatic floaters are not offered any intervention. In this paper we review the efficacy of both Nd:Yag laser and PPV in the surgical treatment of vitreous floaters.

\section{Materials and methods}

\section{Patients}

We reviewed the clinical notes of 31 patients (42 eyes) who underwent 54 procedures, $\mathrm{Nd}$ :YAG vitreolysis or pars plana vitrectomy, for the treatment of vitreous floaters at Stoke
The Department of Ophthalmology Stoke Mandeville Hospital Aylesbury

Buckinghamshire, UK

Correspondence:

L Benjamin

Department of

Ophthalmology

Stoke Mandeville Hospital Aylesbury, Bucks HP21

8AL, UK

Tel: +44 1296315035

Fax: +44 1296315037

E-mail: larrybenjamin@

compuserve.com 
Mandeville Eye Hospital, between January 1992 and December 2000. Patient age, sex, refraction, ophthalmic diagnosis, surgical procedure, post-operative complications and length of follow-up were recorded. Chart review was supplemented by a questionnaire which was sent out to each patient. Statistical analysis was undertaken using Fishers exact test and a $P$ value of $<0.05$ was considered statistically significant.

\section{Questionnaire}

The patients were questioned with regard to duration of their symptoms prior to presentation, laterality, severity and number of their floaters, activity most inconvenienced by the presence of floaters and subjective improvement in symptoms following laser vitreolysis or pars plana vitrectomy. The patients were asked to quantify their post-operative improvement as a percentage as well as choose a descriptive analogy. The options were: (a) Failure: floaters are the same or worse; (b) Partial success: some improvement but still floaters of moderate inconvenience; (c) Significant success: significant improvement with only slight inconvenience; (d) Complete success: complete resolution of floaters. The equivalent percentage improvement was failure $0 \%$, partial success $30-50 \%$, significant success $50-70 \%$ and complete success $100 \%$.

\section{Nd:YAG vitreolysis}

Pre-operative examination of both the vitreous and retina was performed to confirm the presence of a complete PVD, to determine the position of the vitreous opacities and to exclude any co-existing retinal disease. Laser treatment was not undertaken if the vitreous floater/floaters were located within $2 \mathrm{~mm}$ of the retina or the crystalline lens. Pre-operatively eyes were dilated with tropicamide $1 \%$ and phenylephrine $2.5 \%$. Intravitreal laser treatment was performed by the same surgeon (LB) in all cases. The maximum energy used per pulse was $1.2 \mathrm{~mJ}$. A single large floater was lasered directly, disrupting it into smaller fragments. In the presence of multiple opacities, the aim of treatment was to target and disrupt the posterior hyaloid face (to which multiple opacities are attached) so as to encourage further collapse of the vitreous and allow the opacities to re-configure their position more inferiorly within the vitreous cavity. No post-operative topical medication was prescribed. Where treatment was repeated, there was an interval of 2 months between laser sessions.

\section{Pars plana vitrectomy}

A standard three port pars plana vitrectomy was performed under general anaesthesia.

\section{Results}

We analysed the results of 54 surgical procedures on 42 eyes of 31 patients. Fifteen patients were male and 16 were female. The average age was 57.7 years (range 30-86 years). All of the patients had an established posterior vitreous detachment (PVD) which was the primary cause of their floater/s. Three patients had coexisting vitreous veils and two had co-existing asteroid hyalosis. Eleven of the 31 patients had other ocular pathology as shown in Table 1.

\section{Floaters}

Results are summarised in Table 2. The majority of patients (58\%) qualified their floaters as severe with $68 \%$ tolerating their symptoms for more than 6 months prior to seeking an ophthalmological opinion. Twentyfive eyes had one large troublesome floater while 17 eyes had multiple floaters. In $35.4 \%$ they were bilateral. Symptoms were most marked on reading in $45 \%$ of patients, whilst driving in $16 \%$ and all of the time in $39 \%$. Not unexpectedly $71 \%$ of patients were myopic, mean $-3.20 \mathrm{D}$ (range $-0.50 \mathrm{D}$ to $-7.50 \mathrm{D}$ ), $16 \%$ were hypermetropic, mean $+1.10 \mathrm{D}$ (range $+0.50 \mathrm{D}$ to $+1.50 \mathrm{D}$ ), and $13 \%$ were emmetropic. Eleven eyes of 8 patients were pseudophakic with 24.2 months being the average time from cataract surgery to vitreolysis or vitrectomy. The remaining 31 eyes were phakic.

Table 1 Co-existing ocular pathology in patients with floaters

\begin{tabular}{lc}
\hline & No. of patients \\
\hline Retinal break $^{\mathrm{a}}$ & 2 \\
Diabetic retinopathy $^{\mathrm{b}}$ & 1 \\
Fuchs endothelial dystrophy & 1 \\
History of anterior uveitis & 1 \\
Normal tension glaucoma & 1 \\
Ocular hypertension & 1 \\
Juxtapapillary cnv & 1 \\
Previous ocular toxoplasmosis & 1 \\
Stage IV macular hole (other eye) & 1 \\
Toxoplasmosis macular scar (other eye) & 1
\end{tabular}

$\mathrm{cnv}=$ choroidal neovascular membrane

${ }^{\text {aTwo }}$ patients had retinal breaks which had occurred during the acute stage of their PVD. They were both successfully treated with argon laser photocoagulation.

${ }^{b}$ The patient with diabetic retinopathy was a type II diabetic. She had received bilateral panretinal and focal argon laser for proliferative diabetic retinopathy and clinically significant macular oedema respectively, both of which were quiescent at the time of vitreolysis. 
Table 2 Patient demographics and characteristics of their floaters (number (\%))

\begin{tabular}{llllll}
\hline $\begin{array}{l}\text { Pt } \\
\text { No. }\end{array}$ & \multicolumn{1}{c}{ Refraction $^{\text {a }}$} & Severity of symptoms & \multicolumn{1}{c}{$\begin{array}{c}\text { Activity most affected } \\
\text { by floaters }\end{array}$} & \multicolumn{1}{c}{ Laterality } & Phakic status \\
\hline$n=31$ & Myopic 22 (70.9) & Severe 18 (58.1) & Reading 14 (45.1) & Bilateral 11 (35.4) & Phakic 23 (74.1) \\
& Emmetropic 4 (12.9) & Moderate 12 (38.7) & Driving 5 (16.1) & Unilateral 20 (64.5) & IOL 8 (25.8) \\
& Hypermetropic 5 (16.1) & Mild 1 (3.2) & All of the time 12 (39) & & \\
\hline
\end{tabular}

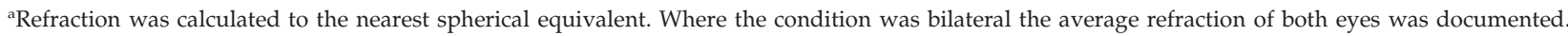
In no patient was there greater than a $0.75 \mathrm{D}$ difference between both eyes.

\section{Laser}

The results are summarised in Table 3. Nd:YAG vitreolysis was the primary treatment in 38 of 42 eyes and the secondary treatment, following pars plana vitrectomy, in one eye. In the latter case (eye No. 19) a single anterior vitreous opacity developed postoperatively secondary to asteroid hyalosis. The average power per treatment session was $310.4 \mathrm{~mJ}$ (range 163$875 \mathrm{~mJ}$ ) with the average treatment sessions per patient numbering 1.62 (range 1-6 sessions). The average total energy delivered to each eye was $501 \mathrm{~mJ}$ (range 163$2752 \mathrm{~mJ}$ ). At an average of 26.6 months follow-up (range 15-53 months) no post-operative complications were recorded. The percentage symptomatic improvement following vitreolysis was as follows: $7.7 \%$ of patients were subjectively worse, $53.8 \%$ were the same, $35.8 \%$ received moderate benefit (30-50\% improvement) while $2.5 \%$ received significant benefit (50-70\% improvement). In no eye was laser treatment $100 \%$ successful in eliminating symptoms. Therefore, overall, no more than 15 eyes benefited from laser. However 14 of these 15 eyes felt that the moderate benefit gained was nevertheless adequate so as to obviate the need for further surgery. Only $6.6 \%$ of improved eyes proceeded to PPV compared to $47.8 \%$ * of eyes that gained no clinical benefit, $P=0.007$. There was no correlation between success and number of treatment sessions $(P=0.05)$, with eyes that benefited from treatment receiving an average of 1.2 sessions $v s$ 1.9 for eyes that failed to respond to treatment. Success was also independent of the number of floaters present $(P=0.2)$, with $43.5 \%$ of single and $31.2 \%$ of multiple floaters associated with improvement following laser.*

\section{Pars plana vitrectomy}

Pars plana vitrectomy was the primary treatment for floaters in four eyes (one with combined phacoemulsification and posterior chamber lens implant for co-existing nuclear white scatter cataract) and the secondary treatment following failure of

\footnotetext{
* Excludes a further $4.3 \%$ who are on the waiting list for PPV.
}

vitreolysis in 11 eyes. In the latter group, two patients' floaters were worse post-vitreolysis, eight were unchanged and one experienced a moderate but inadequate improvement of 30-50\%. Pars plana vitrectomy resulted in full resolution of symptoms in 93.3\%. One patient developed an asteroid hyalosis opacity post PPV for which she underwent unsuccessful Nd:YAG vitreolysis. The average length of follow-up post PPV was 31.5 months (range 6-108 months). One patient developed post-operative cataract and underwent successful phacoemulsification surgery 12 months later. One other patient (eye No. 35, which had a combined procedure) developed a post-operative retinal detachment 7 weeks after surgery. This was successfully treated leaving the patient with 6/5 VA. The retinal detachment was not caused by an entry-site break but by a peripheral retinal break located just posterior to the ora serrata.

\section{Discussion}

Vitreous floaters are most commonly caused by posterior vitreous detachment (PVD) ${ }^{1,2}$ vitreous syneresis $^{2}$ and asteroid hyalosis (AH). ${ }^{3}$ PVD is a separation of the cortical vitreous from the internal limiting membrane of the sensory retina posterior to the vitreous base. Its prevalence increases with axial length and age. ${ }^{4}$ Vitreous syneresis usually precedes the formation of an acute PVD. It also occurs at an earlier age in myopes and can increase in severity following cataract surgery. ${ }^{9}$ It is important to examine the vitreous accurately as vitreous syneresis can mimic the appearance of a posterior vitreous detachment. Asteroid hyalosis is a benign condition in which calcium-lipid complexes form in the collagen meshwork of the vitreous. It affects $0.5-0.9 \%$ of the population ${ }^{10}$ and only rarely causes decreased visual acuity $^{11}$ or symptomatic floaters ${ }^{3}$ on its own. In our patients with $\mathrm{AH}$, they all had a co-existing posterior vitreous detachment.

Vitreous floaters are a frequent symptom. The majority of patients tolerate their symptoms without inconvenience. However there is a significant minority who find their floaters very troublesome, in particular 
Table 3 Analysis of Nd:YAG laser vitreolysis, need for further surgery and length of follow-up in 42 eyes

\begin{tabular}{|c|c|c|c|c|c|c|c|c|c|}
\hline $\begin{array}{l}\text { Eye } \\
\text { No. }\end{array}$ & $\begin{array}{l}\text { No. of } \\
\text { floaters }\end{array}$ & $\begin{array}{l}\text { Total energy } \\
(\mathrm{mJ})\end{array}$ & $\begin{array}{l}\text { No. of laser } \\
\text { Rxs }\end{array}$ & $\begin{array}{c}\text { Follow-up } \\
\text { (months) }\end{array}$ & $\begin{array}{l}\text { Complications } \\
\text { post-vitreolysis }\end{array}$ & $\begin{array}{l}\text { Percentage } \\
\text { improvement } \\
\text { post-laser }\end{array}$ & $P P V$ & $\begin{array}{c}\text { Follow-up } \\
\text { (months) }\end{array}$ & $\begin{array}{c}\text { Complications } \\
\text { post-PPV }\end{array}$ \\
\hline 1 & Single & 2752 & 6 & 33 & None & $0 \%$ & $2^{\circ} \mathrm{PPV}$ & 20 & None \\
\hline 2 & Single & 261 & 1 & 18 & None & $0 \%$ & & & \\
\hline 3 & Multiple & 719 & 2 & 18 & None & Worse & $2^{\circ} \mathrm{PPV}$ & 10 & None \\
\hline 4 & Multiple & 240 & 1 & 18 & None & Worse & $2^{\circ} \mathrm{PPV}$ & 6 & None \\
\hline 5 & Single & 579 & 1 & 24 & None & $0 \%$ & & & \\
\hline 6 & Multiple & 476 & 2 & 23 & None & $0 \%$ & & & \\
\hline 7 & Single & 892 & 2 & 18 & None & $30-50 \%$ & & & \\
\hline 8 & Single & 358 & 1 & 15 & None & $30-50 \%$ & & & \\
\hline 9 & Single & 163 & 1 & 15 & None & $30-50 \%$ & & & \\
\hline 10 & Single & 345 & 2 & 19 & None & $0 \%$ & $2^{\circ} \mathrm{PPV}$ & 16 & None \\
\hline 11 & Multiple & 538 & 1 & 30 & None & $30-50 \%$ & & & \\
\hline 12 & Multiple & 692 & 1 & 30 & None & $30-50 \%$ & & & \\
\hline 13 & Single & 305 & 1 & 42 & None & $30-50 \%$ & & & \\
\hline 14 & Single & $\mathrm{N} / \mathrm{a}$ & $\mathrm{N} / \mathrm{a}$ & $\mathrm{N} / \mathrm{a}$ & $\mathrm{N} / \mathrm{a}$ & $\mathrm{N} / \mathrm{a}$ & $1^{\circ} \mathrm{PPV}$ & 108 & None \\
\hline 15 & Single & 230 & 1 & 23 & None & $0 \%$ & $2^{\circ} \mathrm{PPV}$ & 16 & Lens opacity \\
\hline 16 & Single & 875 & 1 & 36 & None & $50-70 \%$ & & & \\
\hline 17 & Multiple & 342 & 1 & 28 & None & $30-50 \%$ & & & \\
\hline 18 & Multiple & 268 & 1 & 16 & None & $30-50 \%$ & $2^{\circ} \mathrm{PPV}$ & 12 & None \\
\hline 19 & Single & 1873 & 5 & 23 & None & $0 \%$ & Post- $1^{\circ} \mathrm{PPV}$ & 32 & None \\
\hline 20 & Single & 209 & 1 & 21 & None & Worse & & & \\
\hline 21 & Multiple & 346 & 2 & 28 & None & $0 \%$ & & & \\
\hline 22 & Multiple & 357 & 1 & 28 & None & $0 \%$ & & & \\
\hline 23 & Single & 178.7 & 1 & 30 & None & $30-50 \%$ & & & \\
\hline 24 & Single & 290 & 1 & 23 & None & $0 \%$ & & & \\
\hline 25 & Multiple & 426 & 2 & 19 & None & $0 \%$ & & & \\
\hline 26 & Multiple & 519 & 2 & 19 & None & $0 \%$ & & & \\
\hline 27 & Single & 414 & 1 & 16 & None & $30-50 \%$ & & & \\
\hline 28 & Multiple & 216 & 1 & 16 & None & $30-50 \%$ & & & \\
\hline 29 & Multiple & 317 & 1 & 33 & None & $0 \%$ & $\mathrm{w} / 1 \mathrm{PPV}$ & & \\
\hline 30 & Multiple & 664 & 3 & 33 & None & $0 \%$ & $2^{\circ} \mathrm{PPV}$ & 12 & None \\
\hline 31 & Multiple & 202 & 1 & 50 & None & $0 \%$ & $2^{\circ} \mathrm{PPV}$ & 28 & None \\
\hline 32 & Multiple & 250 & 1 & 50 & None & $0 \%$ & & & \\
\hline 33 & Single & 440 & 2 & 33 & None & $30-50 \%$ & & & \\
\hline 34 & Single & 498 & 1 & 28 & None & $0 \%$ & & & \\
\hline 35 & Multiple & $\mathrm{N} / \mathrm{a}$ & $\mathrm{N} / \mathrm{a}$ & $\mathrm{N} / \mathrm{a}$ & $\mathrm{N} / \mathrm{a}$ & $\mathrm{N} / \mathrm{a}$ & $1^{\circ} \mathrm{PPV}^{*}$ & 33 & $\mathrm{RD}$ \\
\hline 36 & Single & 702 & 2 & 52 & None & $30-50 \%$ & & & \\
\hline 37 & Single & 468 & 1 & 21 & None & $30-50 \%$ & & & \\
\hline 38 & Single & 356 & 1 & 18 & None & $0 \%$ & $2^{\circ} \mathrm{PPV}$ & 10 & None \\
\hline 39 & Single & $\mathrm{N} / \mathrm{a}$ & $\mathrm{N} / \mathrm{a}$ & $\mathrm{N} / \mathrm{a}$ & $\mathrm{N} / \mathrm{a}$ & $\mathrm{N} / \mathrm{a}$ & $1^{\circ} \mathrm{PPV}$ & 108 & None \\
\hline 40 & Single & 490 & 2 & 21 & None & $0 \%$ & $2^{\circ} \mathrm{PPV}$ & 18 & None \\
\hline 41 & Single & 660 & 2 & 20 & None & $0 \%$ & & & \\
\hline 42 & Single & 795 & 3 & 53 & None & $0 \%$ & $2^{\circ} \mathrm{PPV}$ & 44 & None \\
\hline
\end{tabular}

Rxs = treatments; $\mathrm{PPV}=$ pars plana vitrectomy $; 1^{\circ} \mathrm{PPV}=$ primary pars plana vitrectomy $; 2^{\circ} \mathrm{PPV}=$ secondary pars plana vitrectomy following unsuccess ful laser vitreolysis; $\mathrm{w} / \mathrm{PPV}=\mathrm{pt}$ on waiting list for pars plana vitrectomy; $1^{\circ} \mathrm{PPV}^{*}=$ primary pars plana vitrectomy combined with phacoemulsification plus posterior chamber lens implantation; $\mathrm{RD}=$ retinal detachment; $\mathrm{N} / \mathrm{a}=$ non-applicable.

young myopes, pseudophakes (in whom improved post-operative contrast sensitivity increases their perception of floaters in the visual field) and patients whose employment requires fine detailed work.

Pre-operatively a thorough vitreo-retinal examination is essential to confirm the presence of a complete PVD and to exclude any retinal breaks. Approximately 1015\% of patients with acute PVD develop retinal tears. Of 163 patients with one or two floaters, Byer ${ }^{12}$ reported $7.3 \%$ had a retinal tear. In our series two out of 42 eyes $(4.8 \%)$ had a retinal tear at their initial presentation and were appropriately treated with argon laser photocoagulation.

Q switched Nd:YAG laser is most commonly used for photodisruption of the posterior capsule following cataract extraction and less frequently for anterior and posterior segment vitreolysis. ${ }^{13,14}$ Application of $\mathrm{Nd}$ :YAG laser for the disruption of vitreous floaters 
has previously been described by several authors. ${ }^{5,6}$ Although low in patient numbers these studies documented high success rates with no post-operative complications. In our hands $\mathrm{Nd}$ :YAG vitreolysis ameliorated symptoms in only a third of patients. Furthermore the clinical improvement was only moderate in degree, subjectively being graded at no greater than $50 \%$ by $93.3 \%$ of patients. In no patient was there complete resolution of symptoms as reported by Tsai et $a l^{5}$ in their paper in 1993. Indeed, laser treatment led to worsening of symptoms in $7.7 \%$ of our patients.

Despite studies describing laser vitreolysis as a treatment for vitreous floaters, this technique does not appear to be widely practised in the UK. The reason for this is unclear but may be a combination of disappointing results, or reluctance to use Nd:YAG laser in the posterior segment. The latter may be influenced by the known complication of retinal detachment following YAG capsulotomy, which occurs at an incidence of between $0.50 \%$ and $4.16 \% .{ }^{15}$ The exact pathogenesis of this complication is unknown but may be related to the generation of a shock wave, vitreous disturbance or the formation of capsular or cellular debris. ${ }^{13}$ The concern is that with intravitreal laser the risk of retinal detachment may be even higher. As in our study, Tsai and Tocozowlski documented no post-operative complications. However Little et $a l_{1}^{14}$ following the use of YAG laser to cut vitreous bands as well as to clear vitreous opacities, reported complications which included focal lens opacities, retinal detachment and minor retinal haemorrhages.

In our laser protocol the presence of an established PVD was essential prior to the undertaking of any treatment and the maximum energy used per pulse was $1.2 \mathrm{~mJ}$. Furthermore no laser was applied if the floater(s) was located within $2 \mathrm{~mm}$ of the retina or crystalline lens. ${ }^{16}$ We believe that by applying these criteria we reduced if not eliminated the risk of retinal damage. Other authors ${ }^{17}$ also recommend the use of specially designed convex-surfaced contact lenses to reduce the energy threshold for plasma formation and so further increase the safety of intravitreal Nd:YAG laser.

Overall, 15 eyes (38.3\%) benefited from laser vitreolysis. Fourteen of these 15 eyes felt that the moderate improvement gained was of a sufficient degree to obviate the need for further surgery. Only $6.6 \%$ of improved eyes proceeded to PPV compared to $47.8 \%$ of eyes that gained no clinical benefit, which was statistically significant. In this study, we found having performed one laser treatment, additional applications were not associated with any further improvement in symptoms.

Pars plana vitrectomy provides a highly effective treatment for floaters with complete resolution of symptoms recorded in $93.3 \%$ of patients. In one patient there was a recurrent post-operative anterior floater (asteroid hyalosis) to which laser vitreolysis was subsequently but unsuccessfully applied.

Pars plana vitrectomy (PPV) is a procedure usually reserved for complicated posterior segment disease. It has a well-known risk profile and justifiably there is reluctance to offer this surgery as a panacea for floaters. However the post-operative complication rate following PPV has been assessed in the setting of retinal detachment surgery or in the presence of complicated vitreo-retinal disease. In our experience pars plana vitrectomy for floaters, in eyes that have an established PVD, is a less complicated procedure with a shorter operating time and theoretically may be associated with a lower incidence of both intraoperative and post-operative complications.

Of our 14 patients who underwent PPV alone, at an average of 31.4 months follow-up, only one postoperative complication of progression of lenticular nuclear sclerosis, was recorded. In one patient, eye No. 35, who had a combined procedure with phacoemulsification, posterior chamber lens implantation and pars plana vitrectomy, a retinal detachment caused by a retinal break located just posterior to the ora serrata developed 7 weeks postoperatively. The retinal detachment was successfully treated leaving the patient with $6 / 5 \mathrm{VA}$.

In summary this paper concludes that $\mathrm{Nd}$ :YAG vitreolysis is a safe but only moderately efficacious procedure that leads to improvement of symptoms in a third of patients. In view of its safety profile, we feel it is worthwhile to offer laser therapy as the primary intervention in the treatment of floaters, as it reduces the number of patients requiring more extensive vitreous surgery. Pars plana vitrectomy should continue to be reserved for those patients who remain markedly symptomatic until future studies further clarify its role in the treatment of patients with floaters and PVD.

\section{References}

1 Murakami K, Jalkh AE, Avila MP, Trempe CL, Schepens CL. Vitreous floaters. Ophthalmology 1983; 90: 1271-1276.

2 Morse PH. Symptomatic floaters as a clue to vitreoretinal disease. Ann Ophthalmol 1975; 7: 865-868.

3 Noda S, Hayasaka S, Setogawa T. Patients with asteroid hyalosis and visible floaters. Jap J Ophthalmol 1993; 37: 452-455

4 Morita H, Funata M, Tokoro T. A clinical study of the 
development of posterior vitreous detachment in high myopia. Retina 1995; 15: 117-124.

5 Tsai WF, Chen YC, Su CY. Treatment of vitreous floaters with neodymium YAG laser. Br J Ophthalmol 1993; 77: 485-488.

6 Toczolowski J, Katski W. Use of Nd:YAG laser in treatment of vitreous floaters. Klinika Oczna 1998; 100: 155-157.

7 Peyman GA, Huamonte FU, Goldberg MF. Pars plana vitrectomy. Vitrectomy treatment of vitreous opacities. Trans Am Acad Ophthalmol Otolaryngol 1976; 81: 394-398.

8 Ghartey KN, Tolentino FI, Freeman HM, et al. Closed vitreous surgery. XVII. Results and complications of pars plana vitrectomy. Arch Ophthalmol 1980; 98: 1248-1252.

9 O'Malley P. The pattern of vitreous syneresis. A study of 800 autopsy eyes. In: Irvine AR, O'Malley C (eds). Advances in Vitreous Surgery. Thomas: Springfield, IL, 1976, pp 17-33.

10 Feist RM, Morris RE, Witherspoon CD, Blair NP, Ticho $\mathrm{BH}$, White MF Jr. Vitrectomy in asteroid hyalosis. Retina 1990; 10: 173-177.

11 Parnes RE, Zakov ZN, Novak MA, Rice TA. Vitrectomy in patients with decreased visual acuity secondary to asteroid hyalosis. Am J Ophthalmol 1998; 125: 703-704

12 Byer NE. Natural history of posterior vitreous detachment with early management as the premier line of defense against retinal detachment. Ophthalmology 1994; 101: 1503-1513; discussion 1513-1514.

13 Jagger JD, Hamilton AM, Polkinghorne P. Q-switched neodymium YAG laser vitreolysis in the therapy of posterior segment disease. Graefes Arch Clin Exp Ophthalmol 1990; 228: 222-225.

14 Little HL, Jack RL. Q switched neodymium: YAG laser surgery of the vitreous. Graefes Arch Clin Exp Ophthalmol 1986; 224: 240-246.

15 Galand A, van Cauwenberge F, Moosavi J. Posterior capsulorhexis in adult eyes with intact and clear capsules. J Cataract Refract Surg 1996; 22: 458-461.

16 Bonner RF, Meyers SM, Gaasterland DE. Threshold for retinal damage associated with the use of high-power neodymium-YAG lasers in the vitreous. Am J Ophthalmol 1983; 96: 153-159.

17 Peyman GA. Contact lenses for Nd:YAG application in the vitreous. Retina 1984; 4: 129-131. 